\title{
EXPERIMENTAL INVESTIGATIONS TO EVALUATE THE VALIDITY AND PERFORMANCE OF NDT PROCEDURES FOR IN-SERVICE INSPECTIONS
}

\author{
H. Makri* \\ University of Msila, Faculty of Technology, Department of Mechanical Engineering, Algeria \\ Laboratory of Materials and structures mechanics, University of Msila, Algeria \\ *Corresponding author's e-mail address: hocine.makri@univ-msila.dz
}

\begin{abstract}
During multipass welding, cumulative and repetitive thermal phenomena may lead to development of cracks that can seriously compromise the quality of the welded joint. The use of Non-Destructive Testing methods is needed for the in-service inspection of the welded joint quality. To reliably evaluate the performance of an NDT procedure for in-service inspections, different types of artificial defects are used for this study. They have to be representative enough in comparison with the real service defects. For instance, thermal crack was realistically created by machining in a welded joint achieved by MAG welding deposition of melted SG3 wire on E36-3 steel, this case study being widely met in the crane industry. The approach consists of comparing two different ultrasonic techniques (Normal beam inspection and Angle beam inspection) in order to evaluate their performance in detecting and determining the size of well-known defects. Despite the difficulty in developing and interpreting the on-screen signals, caused by uncertainty in measuring the defect size, better results have been achieved when the angle beam inspection technique has been applied for the in-service inspections.
\end{abstract}

KEYWORDS: E36-3 steel, Multipass MAG welding, Non-destructive testing.

\section{INTRODUCTION}

Due to its strength, ductility, and weldability, lowalloy structural steel like E36-3 (NFA 36-201) is widely used for the construction of the main components in the Algerian machinery and crane industry. This material is characterized by a uniform refined microstructure which determines an appropriate combination of high strength and excellent toughness [1], [2]. MAG multipass welding is a common method for manufacturing these parts [3], [4]. The feasibility of this technique applied to weld low-alloy high-strength steels has been demonstrated by previous research studies [5].

The multi-pass welding, by its repeated nonuniform heating of the weld zone, followed by cooling at ambient temperature, generates internal stresses that are responsible for the occurrence of different kinds of cracks [6]. To ensure the reliability of the welded mechanical parts and structures, nondestructive welding tests are usually performed. It is well known that non-destructive testing (NDT) methods have to be reliable so that the inspector may be able to determine the quality of the weld [7].

To verify the quality of the in-service ultrasonic (US) weld inspection, several flawed specimens with artificially induced defects are required. These defects, which can be mechanically created, have to be as similar as possible to the ones that could appear in the welded joints. During the ultrasonic inspection, each type of defect emits a specific signal, and consequently the calibration of the inspection device is crucial for the control reliability. The calibration was performed using flawed specimens in which artificial slots were generated. It was decided to use slots because their dimensions can be easily controlled and their geometric shape is close to that of the real cracks that appear in the welded joints.

For testing the reliability of ultrasonic inspection, Pardikar et. al. have generated fatigue cracks with known dimensions ranging from 2.5 to $18 \mathrm{~mm}$ in height and $15 \mathrm{~mm}$ in length. These cracks were subsequently embedded at predetermined locations employing MAG welding. The specimens containing the embedded vertical cracks were examined using two ultrasonic techniques based on transit time: flaw tip echo method and mode conversion method. Excellent agreement between the estimated crack height and the actual crack height was obtained with an accuracy of $\pm 1 \mathrm{~mm}[8]$.

Based on the principle of comparing ultrasonic techniques Keiji Shibata et. al. used reflected and 
diffracted waves at the crack-face or crack-tip. They proposed an imaging technique using an ultrasonic backscattered transverse wave on a crack face. By focusing ultrasonic beams at every peak on those faces with a point-focused transducer and a scanner, as well as by mapping the scattered-wave amplitudes on the scanned plane, they obtained an image of the cracked face. The clarity of the image was improved by using higher harmonic amplitudes [9].

Her et. al. examined the depth of surface crack in a solid using ultrasonic technique. A series of test specimens with various depths of surface crack ranging from $1 \mathrm{~mm}$ to $8 \mathrm{~mm}$ was fabricated. The depth of the surface crack was evaluated using the pulse-echo technique. Three different longitudinal waves with frequencies of $2.25,5$ and $10 \mathrm{MHz}$ were employed to investigate the effect of frequency on the sizing detection of surface cracks. The pulses reflected by the crack were transformed into frequency domain using Fourier transformation technique. The experimental test results obtained by Her et. al. showed that it is helpful to select the ultrasonic transducer with a higher frequency for a short surface crack. For a long surface crack, a lower frequency is more appropriate to achieve a better result. Reasonable accuracy was achieved with measurement errors less than 7\% [10], [11].

Skála et. al. reported that ŠKODA JS has performed automated in-service inspections of the VVER 440 reactor pressure vessels for a long time. All of these inspections were conducted by the ultrasonic pulse-echo method which was combined with eddy current testing. The authors compared the accuracy of detecting a defect by the Time of Flight Diffraction (TOFD) method and by the Pulse-Echo (PE) method. They concluded that for the in-service inspections of VVER reactor parts testing, TOFD is more suitable than the PE method [12].

Ultrasonic Testing (UT) is recommended for both examinations and measurements [13]-[15]. It is obviously that applying appropriate procedures, precise information on the position and dimensions of the defect can be obtained [16], [17]. When an ultrasonic beam of a certain angle meets a defect, an echo is obtained from that defect edge. The height of the defect is geometrically determined by using the refraction angle of the probe and the distance traveled by the beam from the position assigned to the maximum echo value until the end of the defect [8].

\section{MATERIALS AND METHODS}

\subsection{Methods for Sizing Vertical Cracks}

Flaw tip echo method is recommended for sizing surface cracks in welds. This control method can be performed using two techniques: control in normal beam, and control in angle beam [18].

\subsubsection{Control in Normal Beam}

This technique is performed using only longitudinal waves. It is the simplest method that involves impulses generated in normal incidence and echoes collected on the screen device, as figure 1 shows. The estimation of crack position and size, or the ones of any other kind of defect, is based on the comparison between the background echo flight times and the ones of the echo defect. The longitudinal ultrasonic wave that encounters a defect makes the course twice. The travel time $t$ is given by equation (1):

$$
t=2 \cdot d / C
$$

where $d$ is the course of the ultrasound wave (UW) proportional to the defect depth and $C$ is the UW velocity relative to the material.

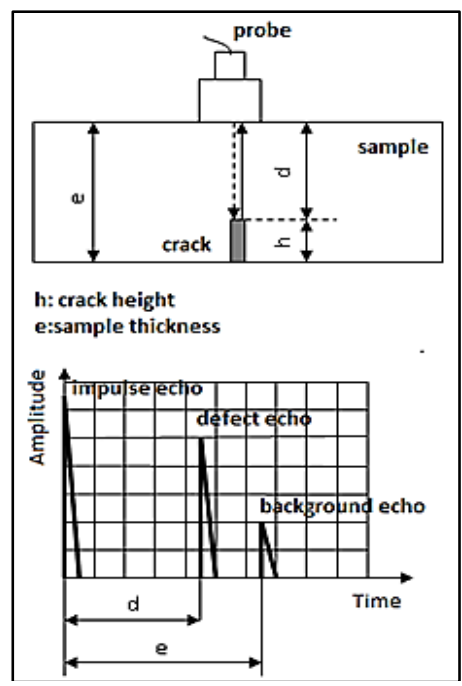

Fig.1. Principle of UT technique in normal incidence

The height of the defect can be deduced based on the equation (2):

$$
h=e-d
$$

where $h$ is the crack height and $e$ the sample thickness

\subsubsection{Control in Angle Beam}

This technique is performed using either longitudinal or transverse waves. However, this method of control is almost exclusively performed in oblique transverse waves. The beam spread angle of the waves, $\alpha$, is greater than $33^{\circ}$, so that only transverse waves can propagate (if angle $\alpha$ is below this value, both transverse and longitudinal waves can be obtained). The detection of faults can be done either in the direct course of the wave, named half-bond control (Fig. 2) or after the rebound of the wave on the sample bottom that is called one bond control (Fig. 3). Generally, there no background echo is detected. 


\subsubsection{Half-bond Control Technique}

This technique, whose principle is presented in figure 2 , is recommended to be used for thick parts $(e>$ $l \cdot \cos \alpha)$. Measuring the defect is based on the geometric projections of the dimensions, where the defect positions, $a$, and the defect height, $h$, can be computed by the equations (3) and (4):

$$
\begin{aligned}
& a=l \cdot \sin \alpha \\
& h=l \cdot \cos \alpha
\end{aligned}
$$

\subsubsection{One Bond Control Technique}

The working principle is presented in figure 3 and it is recommended to be used for the control of the thin parts $(e<l \cdot \cos \alpha)$. The defect can be sized based on the geometric projections of the dimensions. The defect height, $h$, and its position, $a$, can be determined by applying the equation (5) and (6):

$$
\begin{gathered}
h=2 e-l \cdot \cos \alpha \\
a=(I j) \cdot \sin \alpha
\end{gathered}
$$

where: $\quad I j=I m+m j=l+h \cdot \tan \alpha$

The equation (8) is used for determining the defect position $a$, and it is obtained by replacing the equation (7) in the equation (6):

$$
a=l \cdot \sin \alpha-e
$$

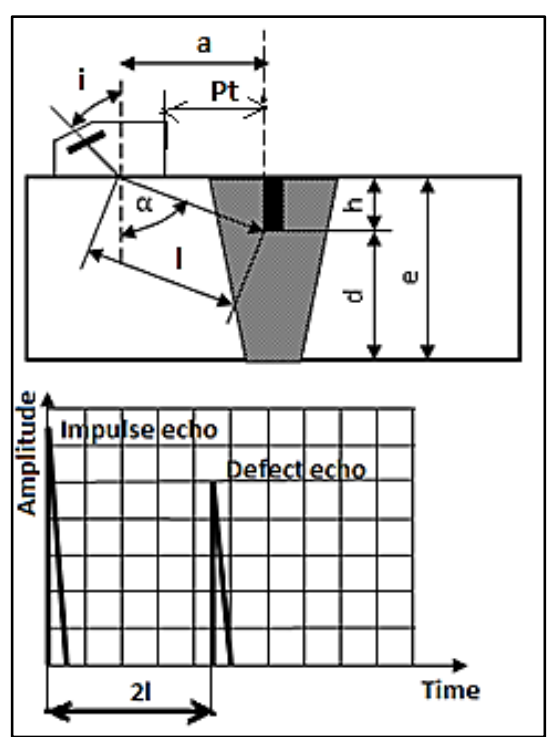

Fig. 2. Principle of the half-bond control technique

\subsubsection{Materials}

A specimen with artificially induced flaws was designed, with the aim of evaluating the performance of the presented ultrasonic techniques, as well as for qualification and for in-service inspection.

Nine holes simulating surface defects were produced in the weld bead axis along the solidification line of an E36-3 steel sheet welded with SG3 wire (AWS A5.18) using MAG welding process. The results obtained were plotted, compared and discussed.

The base material investigated was E36-3 steel that is a low-alloyed structural steel, widely utilized in the machinery industry, and civil construction for cranes, containers, shafts, gears, fingers crawler, machinery structures, devices, components etc. The chemical composition and mechanical properties are presented in the tables 1 and 2 .

The filler metal used in the experimental part was the SG3 (AWS A5.18) which is the recommended wire for welding steels used for boilers, tanks, and metal structures. The chemical composition and mechanical properties of the deposited metal are shown in the tables 3 and 4.

Large size, flat, rough pieces with $12 \mathrm{~mm}$ thickness were mechanically processed with a $60^{\circ} \mathrm{V}$ groove. The pieces were butt-welded by MAG welding, using $\mathrm{CO}_{2}$ as shielding gas. Compared to argon and helium, $\mathrm{CO}_{2}$ gas is cheaper and substantial savings can be achieved. The welding parameters for the root pass and for the filler passes are summarized in Table 5.

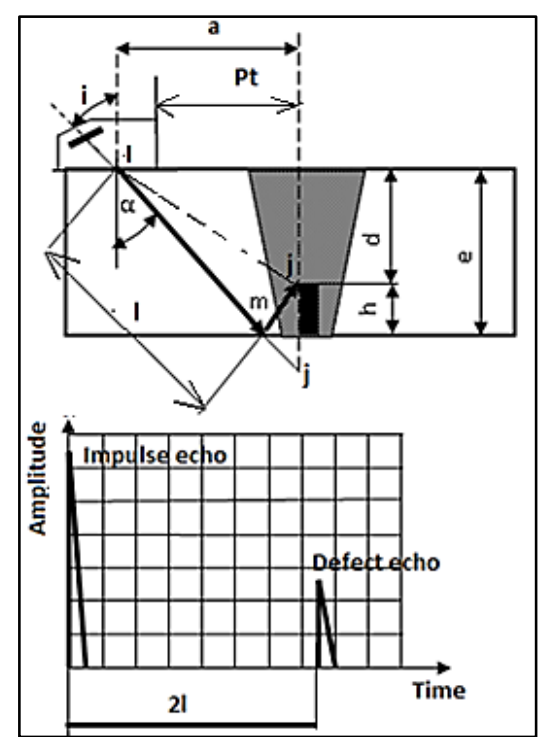

Fig. 3. Principle of one bond control technique

Table 1. Chemical composition of E36-3 steel

\begin{tabular}{|c|c|c|c|c|c|c|c|c|c|c|}
\hline Chemical element & $\mathbf{C}$ & $\mathbf{M n}$ & $\mathbf{S i}$ & $\mathbf{P}$ & $\mathbf{C r}$ & $\mathbf{S}$ & $\mathbf{M o}$ & $\mathbf{A l}$ & $\mathbf{C u}$ & $\mathbf{N i}$ \\
\hline \multirow{2}{*}{ wt [\%] } & $\max$ & $\max$ & $\max$ & $\max$ & $\max$ & $\max$ & \multirow{2}{*}{0.030} & 0.042 & 0.018 & $\max$ \\
& 0.22 & 1.33 & 1.5 & 0.05 & 0.022 & 0.006 & & & \\
\end{tabular}


Table 2. Mechanical properties of E36-3 steel

\begin{tabular}{|c|c|c|c|c|c|}
\hline \multirow{2}{*}{ Mechanical properties } & $\mathbf{R m},[\mathrm{MPa}]$ & $\mathbf{R e},[\mathrm{MPa}]$ & $\mathbf{A},[\%]$ & HB30 & Kvmin $[\mathbf{J}] \mathbf{a t} \pm \mathbf{0}^{\circ} \mathbf{C}$ \\
\cline { 2 - 6 } & $520-620$ & 360 & 16 & $155-185$ & 27 \\
\hline
\end{tabular}

Table 3. Chemical composition of SG3 filler metal

\begin{tabular}{|c|c|c|c|c|c|c|}
\hline $\begin{array}{c}\text { Chemical element } \\
\text { wt, [\%] }\end{array}$ & $\mathbf{C}$ & $\mathbf{M n}$ & $\mathbf{S i}$ & $\mathbf{P}$ & $\mathbf{C u}$ & $\mathbf{S}$ \\
\cline { 2 - 7 } & $0.13 \max$ & $1.9 \max$ & $\begin{array}{c}1.2 \\
\max \end{array}$ & $\begin{array}{c}0.025 \\
\max \end{array}$ & $\begin{array}{c}0.3 \\
\max \end{array}$ & $\begin{array}{c}0.025 \\
\max \end{array}$ \\
\hline
\end{tabular}

Table 4. Mechanical characteristics of SG3 filler metal

\begin{tabular}{|c|c|c|c|c|}
\hline \multirow{2}{*}{ Mechanical Properties } & $\mathbf{R m},[\mathbf{M P a}]$ & $\mathbf{R e},[\mathbf{M P a}]$ & $\mathbf{A},[\mathbf{\%}]$ & $\mathbf{K V}_{\min }[\mathbf{J}]\left(\mathbf{a t} \pm \mathbf{0}^{\circ} \mathbf{C}\right)$ \\
\cline { 2 - 5 } & 620 & 520 & 26 & $>70$ \\
\hline
\end{tabular}

Table 5. MAG welding parameters

\begin{tabular}{|c|c|}
\hline Passes & Welding conditions \\
\hline Root pass & $\mathrm{I}=110 \mathrm{~A}, \mathrm{U}=18 \mathrm{~V}, \phi=0.8 \mathrm{~mm}$, Wire feed speed $=3.2 \mathrm{~m} / \mathrm{min}, 2$ passes \\
\hline Filling pass & $\mathrm{I}=240 \mathrm{~A}, \mathrm{U}=27 \mathrm{~V}, \phi=1.2 \mathrm{~mm}$, Wire feed speed $=9 \mathrm{~m} / \mathrm{min}, 8$ passes \\
\hline
\end{tabular}

For the UT control, two specimens were cut from the butt-welded steel plate with a $12 \mathrm{~mm}$ thickness. The defects were induced in the weld bead axis along the solidification line. They consist of nine equidistant slots, with $5 \mathrm{~mm}$ in diameter. Their depth was increased progressively by one $\mathrm{mm}$, from the first hole that has a $2 \mathrm{~mm}$ depth, to the last one that has a size of $10 \mathrm{~mm}$. These dimensions were confirmed by measurement. Sketches and an image of the prepared samples are illustrated in Fig. 4.

To meet the UT control requirements (ISO 13588, ISO 17640, and ISO 11666), a roughness corresponding to the N10 standard $(12.5 \mu \mathrm{m})$ of the specimens assigned to the technical control is considered generally acceptable. The plate samples do not have a specific geometry.

The inspection of the samples has focused on the size and position of defects, eliminating the geometry effect on the inspected object. The following devices and consumables were employed for the US inspection:

- USL32 ultrasonic wave generator equipped with a Krantkramer plotter;

- MSEB4 transceiver probe with longitudinal waves, capable of controlling thicknesses from 8 to $20 \mathrm{~mm}$, that has the following characteristics: probe diameter $-10 \mathrm{~mm}$, the thickness of the quartz pellet $-3.5 \mathrm{~mm}$, and a frequency of $4 \mathrm{MHz}$;

- MW770-N2 transceiver probe for transverse waves, having the following characteristics: probe diameter - $10 \mathrm{~mm}$, the thickness of the quartz pellet - $3.5 \mathrm{~mm}$, frequency - $2 \mathrm{MHz}$, emerge point - $14 \mathrm{~mm}$, and an angle of incidence of $60^{\circ}$;

- IIW V-1 (A2) ultrasonic block (UT bloc type DIN 54-120 BS2704) for calibration necessary before testing;

- Cellulosic oil as a coupling lubricant that can adequately wet the surface to be inspected.

\subsubsection{Control Conditions}

In order to measure the simulated defects, two control methods were applied: normal beam control, and control in angle beam. For a better precision in reading the signals from the device screen, different scales were chosen for each of these methods:

- normal beam control, the scale was set to $50 / 100$ (range $50 \mathrm{~mm}$ ) for the defects no. 1 to 7, and to 20/100 for the defects 8 and 9;

- control in angle beam, the scale was set to $50 / 82$ (range $50 \mathrm{~mm}$ ), for all the defects.

For the both control methods, a quantitative method of sizing the defects, based on the estimation of the time of flight (TOF) of signals transmitted from the opened defects surfaces, was proposed for the investigation. Thus, the slots size can be estimated by comparing the depth of the slot base with the analysed surface.

To validate the proposed method, a comparative analysis of the results obtained by ultrasonic measurements with the accurate ones obtained by using a comparator was performed. 

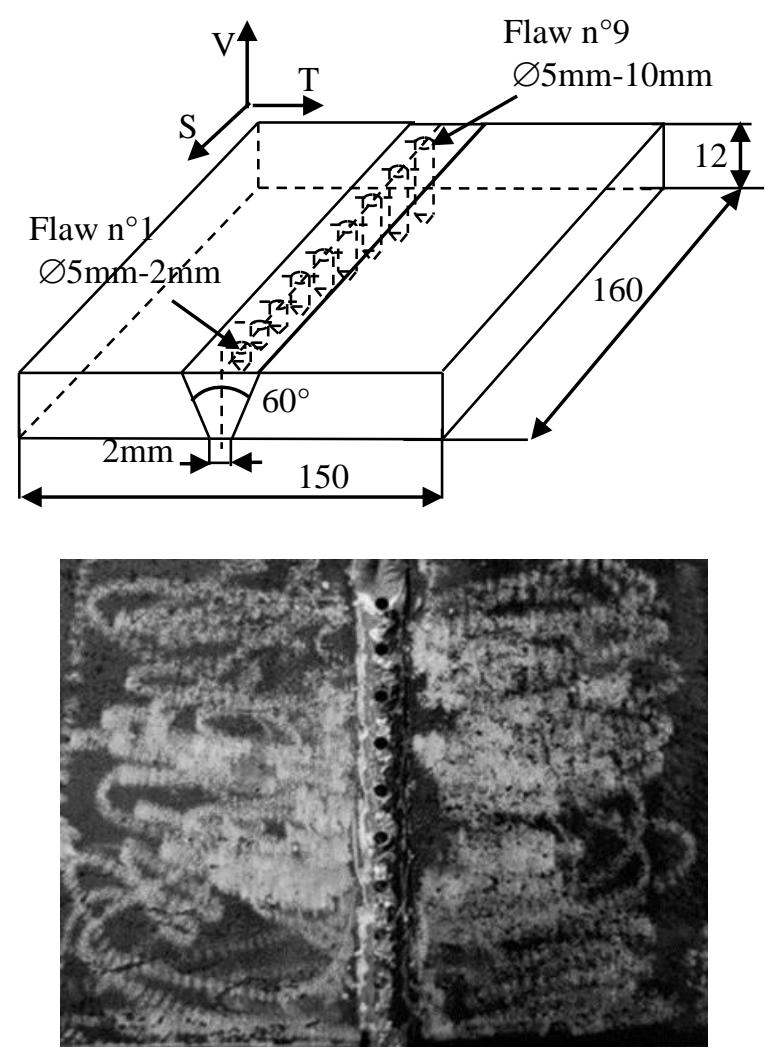

Fig. 4. Sketch and image of specimens prepared for US control

\section{RESULTS AND DISCUSSION}

The calibration process of US devices for normal beam and angle beam led to the following results:

- For the normal beam technique, the background echo was $23.2 \mathrm{~mm}$. The specimen's thickness was obtained from the calculations (thickness $e=$ $1 / 2$ background echo) and the result was about $11.6 \mathrm{~mm}$.

- For the angle beam technique, the bottom echo gave a value of $22.8 \mathrm{~mm}$ at an incidence angle, $\alpha$, of $60^{\circ}$. From the calculation made resulted that the thickness of the specimen was about $11.4 \mathrm{~mm}$ $\left(e=\right.$ Bottom echo $\times \cos 60^{\circ}$ ). The corresponding signal is presented in figure 5 .

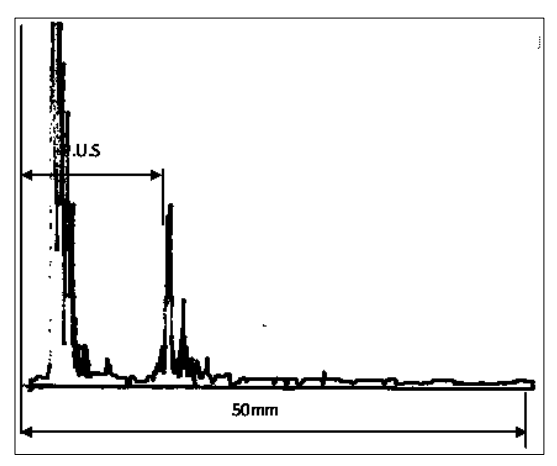

Fig. 5. Plotting of bottom echo in angle beam
The echoes for the normal beam inspection relative to the defects were grouped in figure 6 and those relative to the angle beam technique were grouped in figure 7. The background echo was marked by a dashed arrow while that of the defect was marked by a continuous - line arrow. In the normal beam inspection method, the excitation pulse was recorded at the beginning of the horizontal scale, followed by the defect response and the bottom's echo signals. The difference between the last two signals allows the sizing of the defect. For this technique, it was found that the smaller the defect was, the more disturbed echoes appeared, due to the reflections of the beam on the bottom of the piece. When inspecting the defects 6 and 7, the appearance of the bottom echoes was noticed, these disturbances making their size measurement relatively difficult. The charts reveal that the difference between the real size of the defects and the size measured with the normal beam technique varies from 0.5 to $1.5 \mathrm{~mm}$. These differences, which are considered errors, were attributed to the distortion of the incident beam by the one from the base of the weld, which hinders it or makes it deviate from its trajectory and generates the error. The large difference between the actual size and the measured one, for the 7 th hole, is probably generated by a granular defect or by a crack branching near the end of the defect.

The numeric results of the measurements were centralized in tables 6 and 7. The relative errors that were obtained for the normal beam sizing method are plotted in figures 8 and 9, and the ones obtained by using the angle beam method are represented in figures 10 and 11. For each method of control, histograms were plotted, in order to observe the variation of the relative error measurement, in concordance with the real size of the defect.

In the case of the normal beam control, it was observed that the value of the relative error varies from 8 to $28 \%$. These values are estimated to be too high and, therefore, this technique cannot be considered suitable for detecting small defects when investigating $12 \mathrm{~mm}$ thick plates, and so, supplementary measures must be taken into consideration when the control is performed.

The measurements done with the angle beam technique presented a stable deviation between the real size of the defect and the measured one of about $0.5 \mathrm{~mm}$. The results obtained for the defects no. 4 and 5 were neglected due to the presence of some disturbances. The analysis of the relative error values shows that this method is more accurate in detecting larger defects than small ones. The errors were attributed to the fact that the incident wave is deviated slightly by an interface, or by the orientation of the grain that formed during the weld solidification. This phenomenon was not taken into consideration in the calculation of the US route. Furthermore, the tangent and cosinus functions values were computed for some approximations. 

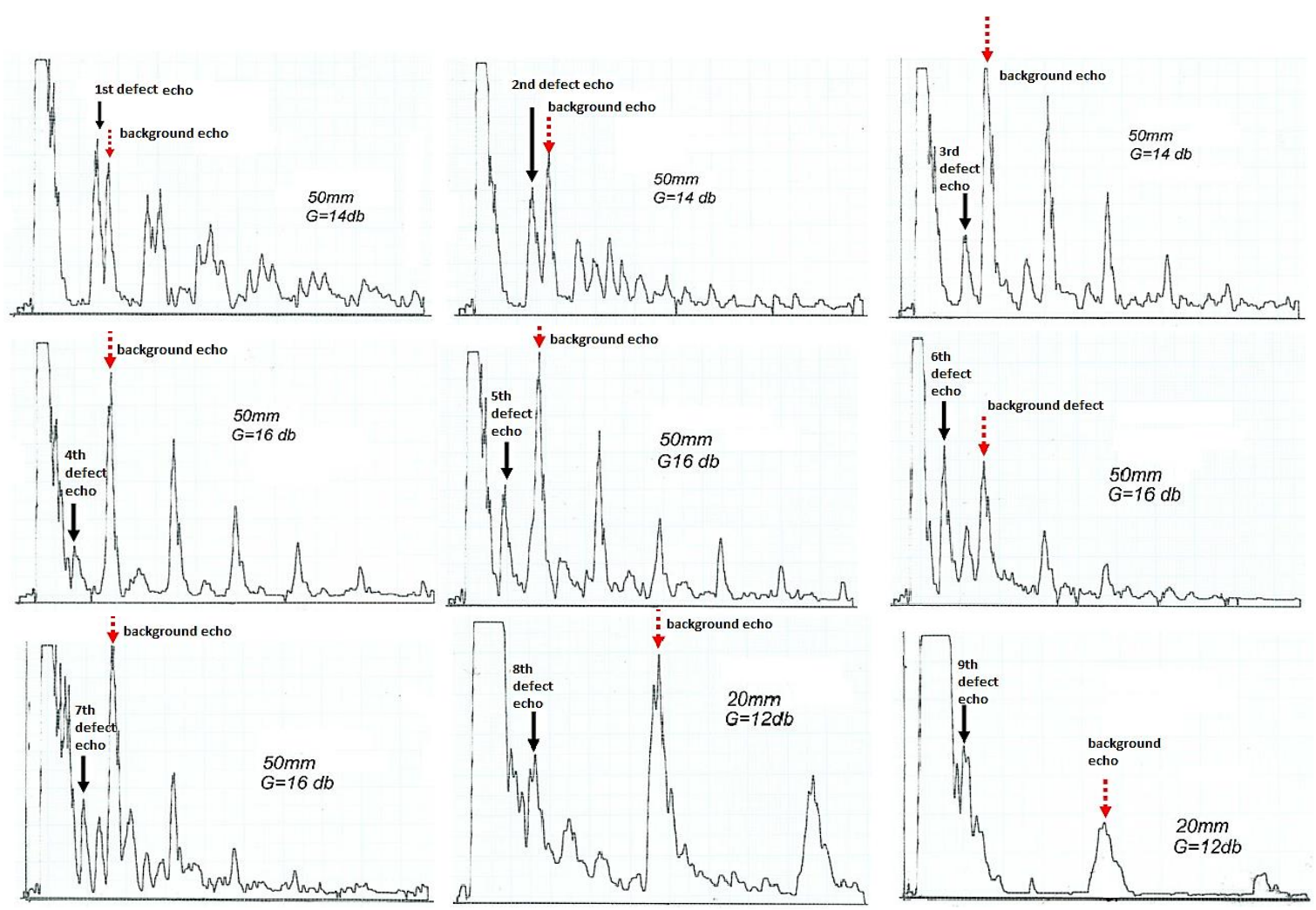

Fig. 6. Plots of ultrasonic echoes of defects performed by normal beam method
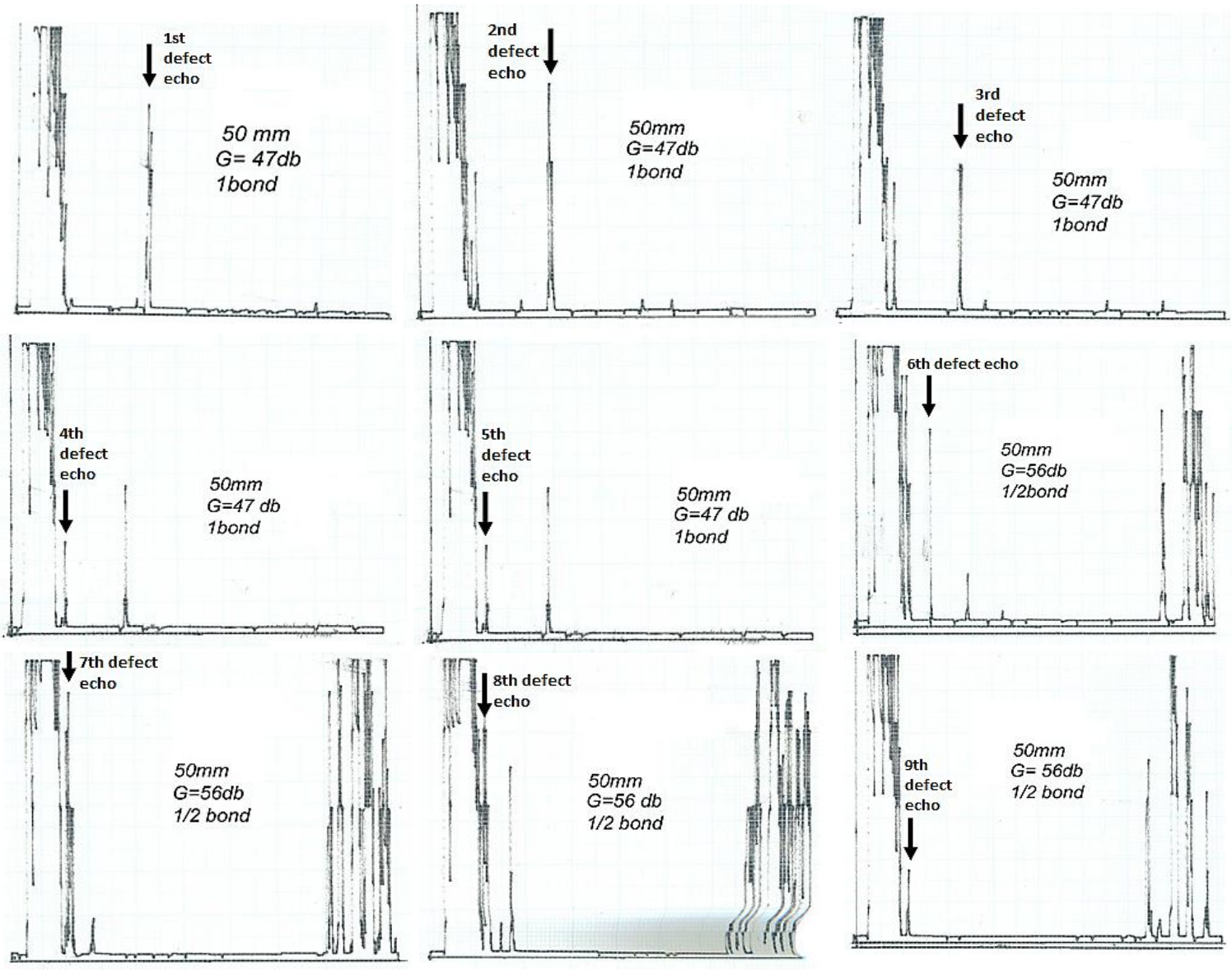

Fig. 7. Plots of ultrasonic echoes of defects performed by angle beam method 
Table 6. US measurements by normal beam method

\begin{tabular}{|c|c|c|c|c|c|c|c|c|c|}
\hline${\text { Defect } \mathbf{n}^{\circ}}^{\circ}$ & $\mathbf{1}$ & $\mathbf{2}$ & $\mathbf{3}$ & $\mathbf{4}$ & $\mathbf{5}$ & $\mathbf{6}$ & $\mathbf{7}$ & $\mathbf{8}$ & $\mathbf{9}$ \\
\hline Real h & 2.05 & 2.9 & 3.8 & 5.1 & 5.95 & 6.75 & 7.8 & 8.4 & 9.5 \\
\hline US measured h & 1.45 & 2.05 & 2.85 & 4.65 & 4.35 & 4.85 & 4.1 & 7.4 & 8.4 \\
\hline $\boldsymbol{\Delta h}$ & 0.6 & 0.85 & 0.95 & 0.45 & 1.6 & 1.9 & 3.7 & 1 & 1.1 \\
\hline $\mathbf{( \Delta \mathbf { h } / \mathbf { h } ) * 1 0 0}$ & 29.76 & 17.24 & 25.0 & 8.82 & 26.89 & 28.14 & 47.43 & 11.9 & 11.57 \\
\hline
\end{tabular}

Table 7. US measurements by angle beam method

\begin{tabular}{|c|c|c|c|c|c|c|c|c|c|}
\hline${\text { Defect } \mathbf{n}^{\circ}}^{\circ}$ & $\mathbf{1}$ & $\mathbf{2}$ & $\mathbf{3}$ & $\mathbf{4}$ & $\mathbf{5}$ & $\mathbf{6}$ & $\mathbf{7}$ & $\mathbf{8}$ & $\mathbf{9}$ \\
\hline Real $\mathbf{h}$ & 2.05 & 2.9 & 3.8 & 5.1 & 5.95 & 6.75 & 7.8 & 8.4 & 9.5 \\
\hline US measured h & 1.58 & 3.01 & 3.32 & 3.47 & 4.692 & 6.22 & 7.16 & 7.74 & 8.35 \\
\hline $\mathbf{\Delta h}$ & 0.47 & 0.11 & 0.42 & 1.63 & 1.258 & 0.53 & 0.64 & 0.66 & 1.15 \\
\hline$(\boldsymbol{\Delta h} / \mathbf{h}) * 100$ & 22.93 & 3.79 & 12.63 & 31.96 & 21.17 & 7.85 & 8.20 & 7.85 & 12.10 \\
\hline
\end{tabular}

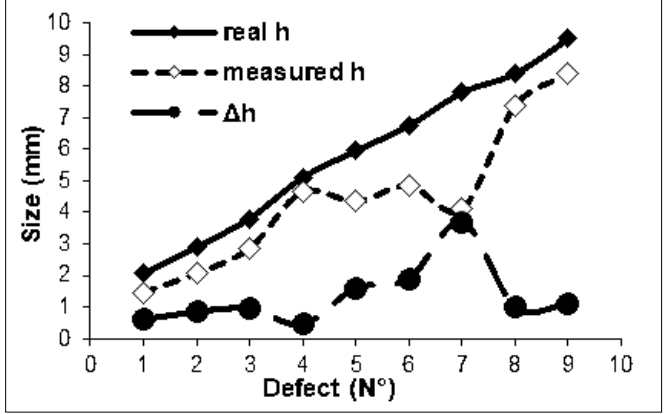

Fig. 8. Normal beam method - measurement results

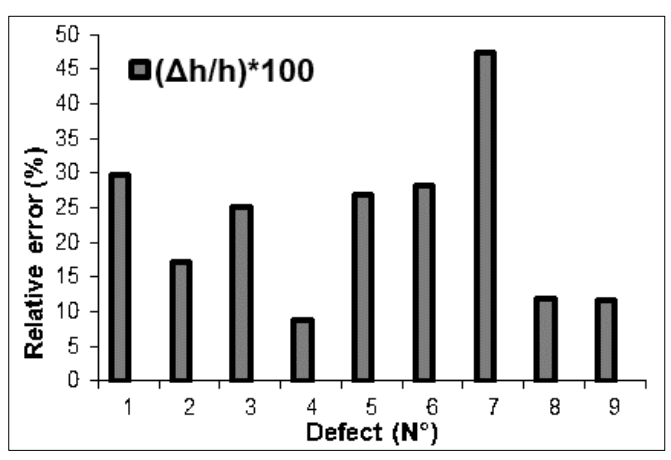

Fig. 9. Histogram of relative error by normal beam

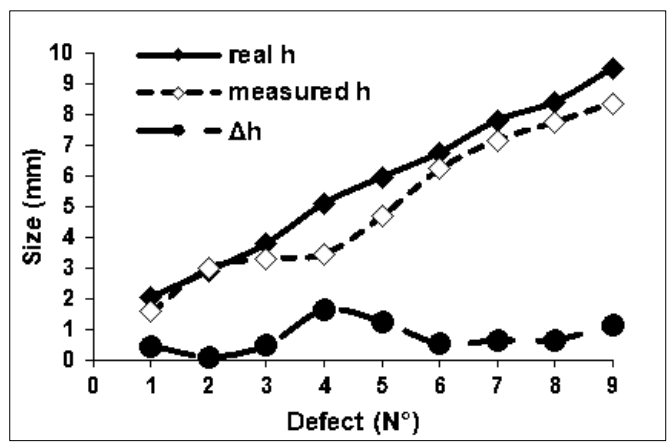

Fig.10. Angle beam method - measurement results

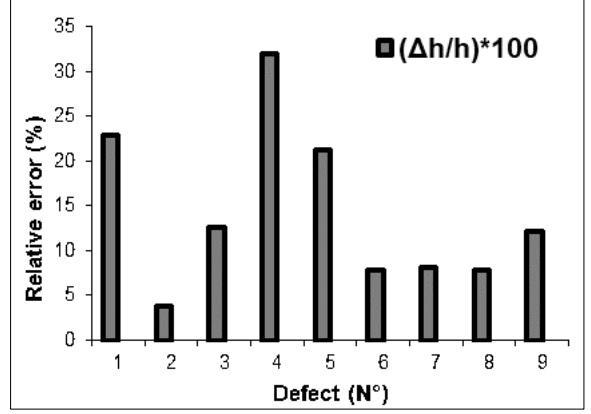

Fig. 11. Histogram of relative error by angle beam

Based on the experimental results, it can be concluded that in the case of large defects, the results achieved by employing the angle beam technique were as good as the results obtained by the normal beam technique.

\section{CONCLUSION}

For determining the defects size by ultrasonic techniques, it has been demonstrated that slots simulating cracks of known size could be generated and embedded in the welds in predetermined locations. In order to analyse how appropriate they are for estimating the position and height of embedded defects, two ultrasonic techniques based on the transit time approach were studied: control in normal beam, and control in angle beam.

The values of the ratios between the real and the estimated heights of defects by two control methods are acceptable. Both methods used in the study have revealed high levels of accuracy from 0.5 to $1.5 \mathrm{~mm}$ for the normal beam method and 0.5 to $1 \mathrm{~mm}$ for the angle beam method.

Because the cracks were embedded at shallow depth, the techniques employed have proven a high degree of accuracy, despite the fact that the measurements of the crack height are influenced by the angle of incidence. 
The results obtained showed that the angle beam control technique seems to be more appropriate for the detection of large defects than for the small ones. On the other hand, the results revealed that the normal beam technique is not suitable for investigating small defects. In this case, the inspection conditions of thick steel plates should be reconsidered. It can be concluded that the angle beam ultrasonic control has been validated for the control of thin pieces made of low-alloy construction steel.

\section{REFERENCES}

[1] Sampath K., An Understanding of HSLA-65 Plate Steels, Journal of Materials Engineering and Performance measurements, vol. 15 , iss. 1, 2006, pp. 32-40.

[2] Makri H., Investigation on microstructure and mechanical properties of E36-3 steel welded joint, Annals of "Dunarea de Jos" University of Galati, FascicleXII. Welding Equipment and Technology, Vol. 27 (Year XXVII), 2016, pp. 47-54.

[3] Mvola B., Kah P., Martikainen J., Dissimilar ferrous metal welding usingadvanced gas metal arc welding processes, Reviews on Advanced Materials Science Journal, vol. 38, 2014, pp. 125-137. [4] Talabi S.I., Owolabi O.B., Adebisi J.A., Yahaya T., Effect of welding variables on mechanical properties of low carbon steel welded joint, Advances in Production Engineering \& Management, vol. 9, no. 04, 2014, pp. 181-186.

[5] Lathabai S., Stout R.D., Shielding Gas and Heat Input Effects on Flux Cored Weld Metal Properties, Supplement to the Welding Journal, November, 1985.

[6] Iordachescu M., Ruiz-Hervias J., Luzin V., Scutelnicu E., Valiente A., Ocaña. J. L., Residual stress distributions in ferritic to austenitic steel joints made by laser welding. The Annals of "Dunarea de Jos" University, FascicleXII, Welding Equipment and Technology, Vol. 24 (Year XXIV), 2013.

[7] Gholizadeh S., A review of non-destructive testing methods of composite materials, Procedia Structural Integrity, vol.1, 2016, pp. $50-57$.
[8] Baby S., Balasubramanian T., Pardikar R.J., Ultrasonic sizing of embedded vertical cracks in ferritic steel welds, Theoretical and Applied Fracture Mechanics, Vol. 40, 2003, pp. 145-151.

[9] Kawashima K., Murase M., Shibata K., Ito T., Backscattered Transverse Wave Imaging of Cracked-Faces with Linear and Nonlinear Ultrasonics, Materials Transactions, Vol. 48, No. 6, 2007, pp. 1202-1207.

[10]Shiuh-Chuan Her and Sheng-Tung Lin., Non-Destructive Evaluation of Depth of Surface Cracks Using Ultrasonic Frequency Analysis, Sensors 2014, 14, pp. 17146-17158.

[11]Her S. C., Lin S. T., Sizing Detection of a Surface-Breaking Crack by Ultrasonic Technique, Applied Mechanics and Materials Vols 52-54, 2011, pp 865-868.

[12]Skála Z., Vít J., Qualification of UT Methods and Systems Used for In-service Inspections of VVER 440 Vessels, Transactions of the 17th International Conference on Structural Mechanics in Reactor Technology (SMiRT 17) Prague, Czech Republic, August 2003, pp. $17-22$.

[13] Charlesworth J. P., Temple J. A. G., Engineering Applications of Ultrasonic Time of Flight Diffraction, Research Studies Press Limited, England, 1989.

[14] Rosenthal I., Sharon Y., Stern A., Multi-material processing: hybrid disk-shaped parts wrought AA6061 \& AM-SLM AlSi $i_{10} M g$, Annals of "Dunarea de Jos" University of Galati, FascicleXII. Welding Equipment and Technology, Vol. 28 (Year XXVIII), 2017, pp. 5-10.

[15]Enav M., Botstein O., Ashkenazi D., Stern A., Characterization of vacuum explosive welded joints between titanium and stainless steel for vacuum applications, Annals of "Dunarea de Jos" University of Galati, FascicleXII. Welding Equipment and Technology, Vol. 29, 2018, pp. 19-26.

[16] Ditchburn R. J., Burke S.K., Scala C.M., NDT of welds: state of the art, NDT \& E International. 1996; 29(2):111-117.

[17]Doyle P. A., Scala C. M., Crack depth measurement by ultrasonics: a review, 0041-624X/78/1604-01645, Ultrasonics, July 1978.

[18] Doyle, P. A. Scala C. M., "Review of Crack Depth Measurement by Ultrasonics", Proceedings of the ARPA/AFML Review of Progress in Quantitative NDE, July 1977. 